\title{
Autopsy Cases of Lung Cancer and Liver Cancer among Japanese Dentists-A Review of the Annual of the Pathological Autopsy Cases in Japan
}

\author{
Nobuhiro NISHIO ${ }^{1 *}$, Hideo TANAKA ${ }^{2}$, Junko NISHIO ${ }^{3}$, \\ Katsuyasu KOUDA ${ }^{4}$ and Tatsuya TAKESHITA ${ }^{1}$ \\ ${ }^{1}$ Department of Public Health, School of Medicine, Wakayama Medical University, 881-1 Kimiidera \\ Wakayama, Wakayama, 641-8509, Japan \\ ${ }^{2}$ Department of Cancer Control and Statistics, Aichi Cancer Center, 1-1 Kanokoden, Chikusa-ku, Nagoya, \\ Aichi 464-8681, Japan \\ ${ }^{3}$ Japan Society of Library and Information Science, 1-2 Kasuga, Tsukuba, Ibaraki 305-8550, Japan \\ ${ }^{4}$ Department of Public Health, Kinki University School of Medicine, 377-2 Ohno-higashi, Osaka-Sayama, \\ Osaka 589-8511, Japan
}

Received February 15, 2008 and accepted April 6, 2011

Published online in J-STAGE August 1, 2011

\begin{abstract}
Dentists are exposed to carcinogenic metals during their work. It has been speculated that dentists are also at high risk for occupational exposure to bloodborne viruses such as hepatitis B and hepatitis C. We suspected that Japanese dentists were at increased risk for lung and liver cancer. To assess this question, we compared the number of pathological diagnoses of lung cancer and liver cancer among autopsy cases of male dentists $(n=225)$ with that among autopsy cases of male medical doctors $(n=1,296)$, based on data from the Annual of the Pathological Autopsy Cases in Japan from 1992 to 1999. We calculated the mortality odds ratio of lung cancer and liver cancer, using stomach cancer as the control. No difference between the dentist group and the medical doctor group was observed in the pathological diagnoses of lung cancer among all autopsy cases $(p=0.703$, Odds Ratio: $0.846,95 \%$ confidence interval: 0.461-1.554). Liver cancer was observed less often among dentists than among medical doctors ( $p=0.047$, Odds Ratio: $0.474,95 \%$ confidence interval: $0.239-0.941$ ). Based on the results of this study, we suggest that Japanese male dentists do not have a higher risk of developing lung cancer than male medical doctors, and have a lower risk of developing liver cancer.
\end{abstract}

Key words: Dentist, Medical doctor, Lung cancer, Liver cancer, Pathological diagnosis

\section{Introduction}

Respiratory dusts are generated at dental clinics during treatment and dental laboratory work ${ }^{1-4)}$. Dental techniques including grinding dental material are included in the role of dentists ${ }^{5,6)}$. Sakuraba reported large amounts of respiratory dusts and scattered around the operator during treatment ${ }^{2}$. Brune and Fukuzawa reported that respiratory dust, chrome, cobalt and nickel

*To whom correspondence should be addressed.

E-mail: nishio@wakayama-med.ac.jp were generated in the dental laboratory room, and measured the volume $3,4,7-10)$. It is assumed that dentists have also been exposed to beryllium during their work as dental technicians ${ }^{11,12)}$. Beryllium, chromium (VI) compounds and nickel compounds are classified as group 1 (Carcinogenic), and cobalt is classified as group 2B (Possibly Carcinogenic) by IARC ${ }^{13-15)}$. Dentists have inhaled and will inhale the dust of these agents during their work. It has been reported that the dust generated through grinding metallic dental materials caused lung disorders in dentists, dental students and dental technicians ${ }^{16-21)}$. A pathological report of a dental techni- 
cian's lung cancer found metal deposit in his lung ${ }^{22)}$.

Hepatitis B virus (HBV) and hepatitis $\mathrm{C}$ virus $(\mathrm{HCV})$ exist in the saliva of infected individuals ${ }^{23}$, 24). Dentists may also be at high risk for occupational exposure to such viruses through the saliva. Infection with $\mathrm{HCV}$, as indicated by the presence of antibodies to $\mathrm{HCV}$ in serum, appeared to be associated with an increased risk for hepatocellular carcinoma ${ }^{25)}$. Japan Dental Association (JDA) advises their member to be aware of hepatitis virus infection among patients in their dental practices $^{26)}$.

We suspected that Japanese dentists were at increased risk for lung and liver cancer. Previously, we reported from a retrospective cohort study that the risk of lung cancer among male members of the Osaka Dental Association (ODA) was equivalent to that among the general population of Osaka Prefecture, and that the risk of liver cancer was lower than that among the general population of Osaka Prefecture; the number of ODA member was assumed to be $7 \%$ of all Japanese dentists during that time period ${ }^{27,28)}$. In our previous study, we counted numbers of lung and liver cancer cases among ODA members, using the Osaka cancer registration, which is largely based on a clinical diagnosis ${ }^{29)}$. Also in our previous study, we compared ODA members and the general male population in Osaka prefecture, and may thus have underestimated socioeconomic confounding factors $\left.{ }^{27}, 28\right)$.

To control for socioeconomics as a confounding factor in the present study, we counted and compared the number of dentists and medical doctors who had lung cancer or liver cancer by pathological diagnosis from a review of the Annual of the Pathological Autopsy Cases in Japan (hereafter referred to as APAC) from 1992 to 1999. It was assumed that dentists and medical doctors had similar social environments.

In Japan, there were several medical investigations based on APAC ${ }^{30-36)}$. Cases in APAC were recorded from pathological diagnoses by board-certificated pathologists. As is often done in clinical diagnosis, cases identifying metastatic cancer as the primary cancer were excluded. Even if they were not a main cause of death, malignant tumors are recorded as the principal pathological diagnosis on APAC, according to regulation. Tsuda presented the possibility of estimating incidence ratio of cases and controls collected from APAC, through a case control study-like design using a mortality odds ratio (MOR) ${ }^{37)}$. In the present study, we counted the number of lung cancer or liver cancer pathological diagnoses among dentists and medical doctors, based on APAC. Subsequently, we calculated the MOR of lung cancer and liver cancer, using stomach cancer as the control. The MOR method has been used in several previous studies and is similar to a classical case-control study ${ }^{38-42)}$. We investigated the risk for lung cancer and liver cancer among Japanese dentists using a more precise pathological diagnosis than clinical diagnosis, and controlled for the socioeconomic factor by comparison with medical doctors.

\section{Material and Methods}

We reviewed APAC data from 1992 to 1999 in order to count the number of dentists who had lung cancer or liver cancer. There were 147,332 male autopsy cases in this period, and the proportion of cases among all male deaths that underwent autopsies was $3.7 \%$.

From APAC data during these $8 \mathrm{yr}$, we extracted all male cases whose current or past jobs were dentist (225 cases) or medical doctor (1,297 cases). There was one medical doctor case with no description of age at the time of death, and this case was therefore excluded from our analysis.

Except for metastatic cancer, we counted the number of dentists and medical doctors who had lung cancer (C34), liver cancer (C22) and stomach cancer (C16) in pathological diagnosis based on the 10th International Diagnostic Related Groups (ICD-10). In the present study, we excluded cholangiocarcinoma and intrahepatic cholangiocarcinoma (C22.1) from liver cancer. We compared the proportion of all lung cancer and liver cancer autopsy cases, between the dentist group and the medical doctor group. Subsequently, we calculated the MOR and 95\% confidence interval (CI) for cases with lung cancer or liver cancer among male dentists compared with male medical doctors. In a case control study that uses the dying cases as control, the cause of their death that relates to the exposure being researched should be excluded ${ }^{43)}$. In our study, we used stomach cancer as control for calculating MOR.

To control for age as a confounding factor, data were analyzed using the Mantel-Haenszel test. Validity of the ordinary $\chi^{2}$ test of association for two categorical variables is usually said to require expected values of at least 4 or 5 for each cell ${ }^{44)}$. To avoid that limitation, we divided the subjects into 2 stratum in liver cancer and 3 stratum in lung cancer by age for the MantelHaenszel test; 2 stratum, below $69 \mathrm{yr}$ of age, and 70 or more years of age; 3 stratum, below $69 \mathrm{yr}$ of age, $70-79 \mathrm{yr}$ of age, 80 or more years of age. We divided the subjects into 4 stratum or less in stomach cancer by age for the Mantel-Haenszel test; 4 stratum, below $59 \mathrm{yr}$ of age, 60-69 yr of age, 70-79 yr of age, 80 or more years of age. Data analyses were performed with the SPSS 15.0J statistical package (SPSS Institute, Tokyo, Japan). 


\section{Results}

The average age of the dentist group was $68.0 \mathrm{yr}$ and that of the medical doctor group was $69.6 \mathrm{yr}$. The age distribution of the dentist group had the highest percentages in the 60 to $69 \mathrm{yr}$ age range $(27.1 \%)$ and the medical doctor group had the highest percentages in the 70 to $79 \mathrm{yr}$ age range $(36.0 \%)$ (Table 1). There was a significant difference in age distribution between the dentist group and the medical doctor group according to the $\chi^{2}$ test $(p=0.000)$, which was calculated by 7 stratums; 20 to $39 \mathrm{yr}$ age range was recalculated as the youngest stratum. We compared the proportion of autopsy cases with lung cancer or liver cancer pathological diagnosis (ICD10 Chapter) between the dentist group and the medical doctor group. In both groups, the principal pathological diagnosis, in descending order, was Neoplasms (Chapter 2), Diseases of the Circulatory System (Chapter 9), Diseases of the Respiratory System (Chapter 10) and Diseases of the Digestive System (Chapter 11) (Table 2).

There were 27 dentists (12\%) and 141 medical doctors $(10.9 \%)$ who had lung cancer by pathological diagnosis. No difference was observed between the dentist

Table 1. Age distribution of male dentists and male medical doctors

$\left.\begin{array}{ccccccccccc}\hline \text { Age group } & 20-29 \mathrm{yr} & 30-39 \mathrm{yr} & 40-49 \mathrm{yr} & 50-59 \mathrm{yr} & 60-69 \mathrm{yr} & 70-79 \mathrm{yr} & 80-89 \mathrm{yr} & \geq 90 \mathrm{yr} & \text { total } \\ \hline \text { Dentists } & 1 & 6 & 24 & 22 & 61 & 54 & 50 & 7 & 225 \\ (\%) & (0.4) & (2.6) & (10.7) & (9.8) & (27.1) & (24.0) & (22.2) & (3.1) & \\ \text { Medical doctors } & 6 & 29 & 56 & 116 & 379 & 466 & 196 & 48 & 1,296\end{array}\right] *$

*Difference was observed between the age distribution among dentist group and the medical doctor group by $\chi^{2}$ test $(p=0.000)$;

Calculating with 7 stratums: 20 to $39 \mathrm{yr}$ age range as the youngest.

Table 2. Number of principal pathological diagnosis by ICD10

\begin{tabular}{|c|c|c|c|c|c|c|}
\hline \multirow[b]{2}{*}{ Chapter } & \multirow[b]{2}{*}{ Blocks } & \multirow[b]{2}{*}{ Title } & \multicolumn{2}{|c|}{ Dentists } & \multicolumn{2}{|c|}{ Medical doctors } \\
\hline & & & number & $\%$ & number & $\%$ \\
\hline I & A00-B99 & Certain infectious and parasitic diseases & 13 & 5.78 & 47 & 3.63 \\
\hline II & C00-D48 & Neoplasms & 139 & 61.78 & 860 & 66.36 \\
\hline III & D50-D89 & $\begin{array}{l}\text { Diseases of the blood and blood-forming organs and certain dis- } \\
\text { orders involving the immune mechanism }\end{array}$ & 5 & 2.22 & 7 & 0.54 \\
\hline IV & E00-E90 & Endocrine, nutritional and metabolic diseases & 13 & 5.78 & 44 & 3.40 \\
\hline V & F00-F99 & Mental and behavioural disorders & 1 & 0.44 & 0 & \\
\hline VI & G00-G99 & Diseases of the nervous system & 5 & 2.22 & 23 & 1.77 \\
\hline VII & H00-H59 & Diseases of the eye and adnexa & 0 & & 0 & \\
\hline VIII & H60-H95 & Diseases of the ear and mastoid process & 0 & & 0 & \\
\hline IX & I00-I99 & Diseases of the circulatory system & 61 & 27.11 & 369 & 28.47 \\
\hline $\mathrm{X}$ & J00-J99 & Diseases of the respiratory system & 52 & 23.11 & 297 & 22.92 \\
\hline $\mathrm{XI}$ & K00-K93 & Diseases of the digestive system & 37 & 16.44 & 221 & 17.05 \\
\hline XII & L00-L99 & Diseases of the skin and subcutaneous tissue & 1 & 0.44 & 0 & \\
\hline XIII & M00-M99 & Diseases of the musculoskeletal system and connective tissue & 5 & 2.22 & 16 & 1.23 \\
\hline XIV & N00-N99 & Diseases of the genitourinary system & 11 & 4.89 & 32 & 2.47 \\
\hline $\mathrm{XV}$ & O00-O99 & Pregnancy, childbirth and the puerperium & 0 & & 0 & \\
\hline XVI & P00-P96 & Certain conditions originating in the perinatal period & 0 & & 0 & \\
\hline XVII & Q00-Q99 & $\begin{array}{l}\text { Congenital malformations, deformations and chromosomal } \\
\text { abnormalities }\end{array}$ & 1 & 0.44 & 1 & \\
\hline XVIII & R00-R99 & $\begin{array}{l}\text { Symptoms, signs and abnormal clinical and laboratory findings, } \\
\text { not elsewhere classified }\end{array}$ & 0 & & 7 & 0.54 \\
\hline XIX & S00-T98 & $\begin{array}{l}\text { Injury, poisoning and certain other consequences of external } \\
\text { causes }\end{array}$ & 2 & 0.89 & 8 & 0.62 \\
\hline $\mathrm{XX}$ & V01-Y98 & External causes of morbidity and mortality & 0 & & 2 & 0.15 \\
\hline XXI & Z00-Z99 & $\begin{array}{l}\text { Factors influencing health status and contact with health ser- } \\
\text { vices }\end{array}$ & 0 & & 0 & \\
\hline XXII & U00-U99 & Codes for special purposes & 0 & & 3 & 0.23 \\
\hline \multicolumn{3}{|c|}{ Number of pathological diagnosis } & 346 & 1.54 per person & 1,937 & 1.49 per person \\
\hline \multicolumn{3}{|c|}{ Number of people } & 225 & & 1,296 & \\
\hline
\end{tabular}


group and the medical doctor group in the proportion of pathological diagnosis of lung cancer among all autopsy cases (Mantel-Haenszel analysis by age class, $p=0.614$, Odds Ratio (OR): 1.151, 95\%CI: 0.739-1.794). There were 15 dentists $(6.7 \%)$ and 148 medical doctors (11.4\%) who had liver cancer by pathological diagnosis. Liver cancer was observed less often among dentists than among medical doctors (Mantel-Haenszel test, $p=0.033$; OR: 0.536, 95\%CI: 0.309-0.931). There were 28 dentists $(12.4 \%)$ and 130 medical doctors $(10.0 \%)$ who had stomach cancer by pathological diagnosis. No difference was observed between the dentist group and the medical doctors (Mantel-Haenszel test, $p=0.547$, OR: 1.173, 95\%CI: 0.759-1.815). (Table 3) There was no lung cancer, liver cancer or stomach cancer cases among the 20-29 yr age group.

We calculated the MOR of lung cancer and liver cancer, using stomach cancer as the control. No difference between the dentist group and the medical doctor group was observed in the lung cancer diagnoses among autopsy cases ( $p=0.649$, OR: $0.833,95 \%$ CI: $0.462-1.502$ ) (Table 4a). Liver cancer was observed less often among dentists than among medical doctors $(p=0.043$, OR: 0.470 , 95\%CI: 0.237-0.930) (Table 5a).

Table 3. Age distribution of lung cancer, stomach cancer and liver cancer among male dentists and male medical doctors

\begin{tabular}{|c|c|c|c|c|c|c|c|c|c|}
\hline & Age group & $30-39$ yr & $40-49$ yr & $50-59 \mathrm{yr}$ & $60-69 \mathrm{yr}$ & $70-79 \mathrm{yr}$ & $80-89$ yr & $\geq 90 \mathrm{yr}$ & total \\
\hline \multirow[t]{2}{*}{ Lung cancer } & $\begin{array}{c}\text { Dentists } \\
(\%)\end{array}$ & 0 & $\begin{array}{c}2 \\
(8.3)\end{array}$ & 0 & $\begin{array}{c}6 \\
(9.8)\end{array}$ & $\begin{array}{c}9 \\
(16.7)\end{array}$ & $\begin{array}{c}10 \\
(20.0)\end{array}$ & 0 & $\begin{array}{c}27 \\
(12.0)\end{array}$ \\
\hline & $\begin{array}{c}\text { Medical doctors } \\
(\%)\end{array}$ & $\begin{array}{c}1 \\
(3.4)\end{array}$ & $\begin{array}{c}4 \\
(7.1)\end{array}$ & $\begin{array}{c}7 \\
(6.0)\end{array}$ & $\begin{array}{c}36 \\
(9.5)\end{array}$ & $\begin{array}{c}61 \\
(13.1)\end{array}$ & $\begin{array}{c}24 \\
(12.2)\end{array}$ & $\begin{array}{c}8 \\
(16.7)\end{array}$ & $\begin{array}{c}141 \\
(10.9)\end{array}$ \\
\hline \multirow[t]{2}{*}{ Liver cancer } & $\begin{array}{c}\text { Dentists } \\
(\%)\end{array}$ & 0 & $\begin{array}{c}2 \\
(8.3)\end{array}$ & $\begin{array}{c}3 \\
(13.6)\end{array}$ & $\begin{array}{c}4 \\
(6.6)\end{array}$ & $\begin{array}{c}6 \\
(11.1)\end{array}$ & 0 & 0 & $\begin{array}{l}15 \\
(6.7)\end{array}$ \\
\hline & $\begin{array}{c}\text { Medical doctors } \\
(\%)\end{array}$ & $\begin{array}{c}1 \\
(3.4)\end{array}$ & $\begin{array}{c}2 \\
(3.6)\end{array}$ & $\begin{array}{c}18 \\
(15.5)\end{array}$ & $\begin{array}{c}65 \\
(17.2)\end{array}$ & $\begin{array}{c}50 \\
(10.7)\end{array}$ & $\begin{array}{c}11 \\
(5.6)\end{array}$ & $\begin{array}{c}1 \\
(2.1)\end{array}$ & $\begin{array}{c}148 \\
(11.4)\end{array}$ \\
\hline \multirow[t]{2}{*}{ Stomach cancer } & $\begin{array}{l}\text { Dentists } \\
(\%)\end{array}$ & 0 & $\begin{array}{c}1 \\
(4.2)\end{array}$ & $\begin{array}{c}4 \\
(18.2)\end{array}$ & $\begin{array}{c}6 \\
(9.8)\end{array}$ & $\begin{array}{c}9 \\
(16.7)\end{array}$ & $\begin{array}{c}8 \\
(16.0)\end{array}$ & 0 & $\begin{array}{c}28 \\
(12.4)\end{array}$ \\
\hline & $\begin{array}{c}\text { Medical doctors } \\
(\%)\end{array}$ & $\begin{array}{c}3 \\
(10.3)\end{array}$ & $\begin{array}{c}6 \\
(10.7)\end{array}$ & $\begin{array}{c}11 \\
(9.5)\end{array}$ & $\begin{array}{c}33 \\
(8.7)\end{array}$ & $\begin{array}{c}58 \\
(12.4)\end{array}$ & $\begin{array}{c}15 \\
(7.7)\end{array}$ & $\begin{array}{c}4 \\
(8.3)\end{array}$ & $\begin{array}{c}130 \\
(10.0)\end{array}$ \\
\hline
\end{tabular}

* No difference was observed between the dentist group and the medical doctor group in the proportion of pathological diagnosis of lung cancer using the Mantel-Haenszel test categorized into 3 groups, $69 \mathrm{yr}$ of age and younger, 70-79 yr, $80 \mathrm{yr}$ old and older $(p=0.614)$.

(Odds ratio : $1.151,95 \%$ confidence interval: $0.739-1.794$ )

Liver cancer was observed less often among dentists than among medical doctors using the Mantel-Haenszel test categorized into 2 groups, $69 \mathrm{yr}$ of age and younger, $70 \mathrm{yr}$ old and older. $(p=0.033)$.

(Odds ratio : 0.536, 95\% confidence interval: 0.309-0.931)

INo difference was observed between the dentist group and the medical doctor group in the proportion of pathological diagnosis of stomach cancer using the Mantel-Haenszel test categorized into 4 groups, $59 \mathrm{yr}$ of age and younger, 60-69 yr, 70-79 yr, 80 yr old and older.

$(p=0.547)$. (Odds ratio : $1.173,95 \%$ confidence interval: $0.759-1.815$ )

(\%) Proportion of the cancer among subjects in that age group.

There is no lung cancer, liver cancer or stomach cancer among the 20-29 yr age group.

Table 4. Age distribution of Lung cancer and Stomach cancer among male dentists and male medical doctors for MOR (4a). $4 \mathrm{~b}$ shows the same distribution excluding subjects who had both lung cancer and stomach cancer.

$4 \mathrm{a}^{*}$

\begin{tabular}{lccccr}
\hline & Age group & $\leq 69 \mathrm{yr}$ & $70-79 \mathrm{yr}$ & $\geq 80 \mathrm{yr}$ & total \\
\hline Lung cancer & Dentists & 8 & 9 & 10 & 27 \\
& Medical doctors & 48 & 61 & 32 & 141 \\
\hline \multirow{2}{*}{ Stomach cancer } & Dentists & 11 & 9 & 8 & 28 \\
& Medical doctors & 53 & 58 & 19 & 130 \\
\hline
\end{tabular}

$4 \mathrm{~b}^{\dagger}$

\begin{tabular}{lccrrr}
\hline & Age group & $\leq 69 \mathrm{yr}$ & $70-79 \mathrm{yr}$ & $\geq 80 \mathrm{yr}$ & total \\
\hline Lung cancer & Dentists & 8 & 9 & 8 & 25 \\
& Medical doctors & 47 & 56 & 31 & 134 \\
\hline \multirow{2}{*}{ Stomach cancer } & Dentists & 11 & 9 & 6 & 26 \\
& Medical doctors & 52 & 53 & 18 & 123 \\
\hline
\end{tabular}

* No difference between the dentist group and the medical doctor group was observed in the lung cancer diagnoses among autopsy cases using the Mantel-Haenszel test categorized into 3 groups, below $69 \mathrm{yr}, 70-79 \mathrm{yr}, 80 \mathrm{yr}$ old and older. $(p=0.649)$

(Odds ratio : $0.833,95 \%$ confidence interval: $0.462-1.502$ )

${ }^{\dagger}$ No difference between the dentist group and the medical doctor group was observed in the lung cancer diagnoses among autopsy cases using the Mantel-Haenszel test categorized into 3 groups, below $69 \mathrm{yr}, 70-79 \mathrm{yr}, 80 \mathrm{yr}$ old and older. $(p=0.703)$

(Odds ratio : $0.846,95 \%$ confidence interval: $0.461-1.554$ ) 
Table 5. Age distribution of Liver cancer and Stomach cancer among male dentists and male medical doctors for MOR (5a). 5b shows the same distribution excluding subjects who had both liver cancer and stomach cancer $5 \mathrm{a}^{*}$

\begin{tabular}{lcccr}
\hline & Age group & $\leq 69 \mathrm{yr}$ & $\geq 70 \mathrm{yr}$ & total \\
\hline Liver cancer & Dentists & 9 & 6 & 15 \\
& Medical doctors & 86 & 62 & 148 \\
\hline Stomach cancer & Dentists & 11 & 17 & 28 \\
& Medical doctors & 53 & 77 & 130
\end{tabular}

$5 b^{\dagger}$

\begin{tabular}{lcccc}
\hline & Age group & $\leq 69 \mathrm{yr}$ & $\geq 70 \mathrm{yr}$ & total \\
\hline Liver cancer & Dentists & 9 & 6 & 15 \\
& Medical doctors & 85 & 55 & 141 \\
\hline \multirow{2}{*}{ Stomach cancer } & Dentists & 11 & 17 & 28 \\
& Medical doctors & 52 & 70 & 122 \\
\hline
\end{tabular}

* Liver cancer was observed less often among dentists than among medical doctors using the Mantel-Haenszel test categorized into 2 groups, below $69 \mathrm{yr}, 70 \mathrm{yr}$ old and older. $(p=0.043)$ (Odds ratio : $0.470,95 \%$ confidence interval: $0.237-0.930$ )

${ }^{\dagger}$ Liver cancer was observed less often among dentists than among medical doctors using the Mantel-Haenszel test categorized into 2 groups, below $69 \mathrm{yr}, 70 \mathrm{yr}$ old and older. $(p=0.047)$

(Odds ratio : 0.474, 95\% confidence interval: 0.239-0.941).

Two dentists had both primary lung cancer and primary stomach cancer. No dentist had both primary liver cancer and primary stomach cancer. Seven medical doctors had both primary lung cancer and primary stomach cancer. Eight medical doctors had both primary lung cancer and primary stomach cancer. Excluding those case, we also calculated the MOR of lung cancer and liver cancer, using stomach cancer as the control. Again, no difference between the dentist group and the medical doctor group was observed in the lung cancer diagnoses among autopsy cases $(p=0.703$, OR: 0.846 , 95\%CI: 0.461-1.554) (Table 4b). Liver cancer was observed less often among dentists than among medical doctors $(p=0.047$, OR: $0.474,95 \%$ CI: $0.239-0.941)$ (Table 5b).

No case had multiple primary lung cancers or multiple primary liver cancers. One medical doctor had double primary stomach cancer; for calculating the MOR, we counted this as one stomach cancer case.

\section{Discussion}

In the present study, we compared the proportion of the disease and calculated MOR based on pathological diagnosis, which should provide a more reliable estimate than based on clinical diagnosis. Pathological diagnosis is considered to be more exact and reliable than a clinical diagnosis ${ }^{33,45)}$, and can often detect occult cancers that are missed when diagnosis is based on clinical symptoms ${ }^{30,46)}$.

In Japan, there were several medical investigations based on APAC. However, with the use of APAC, there are some limitations in our study. Yamamoto assumed that cases in APAC were not extracted through random sampling, but instead were extracted from a population with death caused by several disease, each with its own individual extracting rate ${ }^{33)}$. Cases on APAC are almost always reported from hospitals at which a board certified pathologist belonging to the Japan Association of Pathology is working. Therefore, selection bias can occur because the cases in APAC are presented under the informed consent by relatives of deceased for pathological autopsy by the medical doctor. It is assumed that cases with lung cancer and liver cancers selectively undergo pathological autopsy more often cases with other disease ${ }^{45)}$.

Since 2000, in APAC, occupation status of the cases has been transcribed by categories, and it has been impossible to distinguish the case of dentists from those of medical doctors. Until 1999, APAC had depended on the pathological report description of the past occupation of the dentists or medical doctors; for example retired dentists, retired medical doctor or unemployed. It is assumed that neither medical doctors in the past nor dentists in the past were transcribed as unemployed as their pathological reports were far less likely to describe their occupations as unemployed compared to the reports of other people's past occupations. In our study, we compared the dentists with medical doctors, both of which were extracted from APAC by the same method; therefore, it was assumed that the healthy worker effect, if it occurred, was not large $\mathrm{e}^{47)}$.

Both in dentists and medical doctors, the most frequent principal pathological diagnosis was Neoplasms (Chapter 2; 61.8\%, 66.4\%). In this study, we did not investigate the pathological diagnosis of whole male autopsy cases from APAC. Tomioka counted pathological diagnosis of 1,806 male autopsy cases extracted from APAC, and found malignant neoplasm in $63 \%$ $(1,151 / 1,806)$. The frequency of pathological diagnosis among whole male cases might be similar to the male dentist cases or male medical doctors.

In this study, we compared cases with lung cancer and liver cancer in dentists and medical doctors by a case control study-like method using MOR. In the case control study, overlap among the case group and 
the control group was not allowed. For calculating the MOR, we excluded cases that had both lung cancer and stomach cancer, or liver cancer and stomach cancer; there was no clear difference regardless of whether cases were excluded or not excluded (Tables $4 \mathrm{a}, 4 \mathrm{~b}, 5 \mathrm{a}$, $5 b)$.

It was assumed that dentists and medical doctors had similar social environments. Until 2005, only dentists and medical doctors were required to study $6 \mathrm{yr}$ of school coursework to get a license in Japan. In Japan, the occupational prestige score of dentists and medical doctors are same ${ }^{48,49)}$. We assumed that there was no difference in socioeconomic factors among dentists and medical doctors.

Based on the results of this study, Japanese dentists do not have a higher risk of developing lung cancer than medical doctors. This result is compatible with our past findings ${ }^{27)}$. Ikuta studied the insurance bill data on the Tokyo Dental Association (TDA) members and showed that the Standardized Mortality Ratio (SMR) of lung cancer was 0.96 ; the study was compared with the Tokyo male population, the Japanese male working population and the Japanese male population ${ }^{50)}$. Niwa examined similar insurance bill data on the JDA members, and showed that the SMR of lung cancer was 0.71; the study was compared with the Japanese male population $^{51)}$. In previous studies conducted in Finland ${ }^{52)}$ and Sweden ${ }^{53)}$, dentists did not have an elevated risk for lung cancer; the Finnish study was compared with the general working population and the Swedish study was compared with general population. Our results agree with the findings of these studies. Tomioka, using APAC data from 1980 to 1984 , reported that there have been less pathological diagnoses of trachea, bronchus and lung cancer in medical doctors compared with the general population ${ }^{31}$.

The present study showed that the proportion of liver cancer among male dentists was significantly lower than that among medical doctors, based on APAC data. Ikuta studied the data of the TDA members by insurance bills and showed that the SMR of liver cancer was $0.51^{50)}$. Niwa examined similar data of the JDA members by insurance bills and showed that the SMR of liver cancer was $0.62^{51)}$. Again, our results agree with the findings of these studies. In previous studies conducted in Finland ${ }^{52)}$ and Sweden ${ }^{53)}$, dentists did not have an elevated risk for liver cancer. Few reports are known about mortality or incidence among Japanese dentists. Tomioka, using APAC data from 1980 to 1984, reported that there might have been more pathological diagnoses of liver disease in medical doctors compared with the general population, but no significant difference was seen in the rate of liver cancer ${ }^{31}$.
Regarding the causes of liver cancer among males in Osaka prefecture, it has been reported that $15 \%$ of the cases were caused by chronic HBV infection and 75\% were caused by chronic HCV infection ${ }^{54)}$. It has been said that both medical doctors and dentists have higher infection rates of $\mathrm{HBV}$ and $\mathrm{HCV}$ than the general population, but large-scale investigations have not been reported $^{55,56)}$. Toyota reported that there was no case of seroconversion of HCV antibody among eight dental workers who had suffered stab accidents while working on $\mathrm{HCV}$ positive patients ${ }^{57)}$. Our results, together with this previous report on stab accidents in dentistry, support the notion that the probability of HCV transmission into a dentist's fingertip from the patient's saliva was low even before universal precautions were established in Japan. On the contrary, there were no reports on how often transmission of HCV virus has occurred in dentists whose clinical practice included treatment of patients with $\mathrm{HCV}$.

Based on the results of this study, we suggest that Japanese male dentists have a lower risk of developing liver cancer than medical doctors. The reason for this lower incidence of liver cancer among dentists is unknown. There is a difference in the prevalence of liver cancer between eastern and western Japan, but differences in distribution of the areas of residence between dentists and medical doctors whom we investigated were not seen ${ }^{54}$.

The smoking prevalence of male members of Hyogo Dental Association in 1997 (38.5\%) was lower than that of the general population, and it was assumed that the smoking prevalence of male medical doctors in 2000 $(27.1 \%)$ was also lower than that of general population $^{58,59)}$. Kaetsu reported that the smoking prevalence of male physicians in Fukuoka was $43.4 \%$ in $1983^{60)}$. There are few medical reports that suggested the smoking prevalence of dentists or medical doctors in 1970s and 1980s might have affected the autopsy cases of lung cancer such as those that were observed in the present study.

It has also been reported that both medical doctors and dentists drink less than the male general population $^{61,62)}$. Takei reported that the proportion of frequent drinkers among dental students (16.1\%), who drink every other day or more, was more than that among other college students $(9.7 \%)^{63)}$. However, there are few medical reports that suggest the drinking habits of dentists or medical doctors in the 1970s and 1980s might have affected the autopsy cases of liver cancer such as those that were observed here.

In the present study, we excluded cholangiocarcinoma and intrahepatic cholangiocarcinoma (C22.1) from liver cancer. It has been reported that HCV related cirrho- 
sis is a risk factor for primary cholangiocellular carcinoma of the liver (PCC-L) in Japanese patients ${ }^{64,65)}$. However, it is assumed that the risk factors for PCC-L have not been fully investigated. In the present study, no dentist or medical doctor had hepatic hemangiosarcoma (C22.3).

\section{Conclusion}

Based on data from the APAC from 1992 to 1999, it is suggested that Japanese male dentists do not have a higher risk of developing lung cancer than male medical doctors, and have a lower risk of developing liver cancer than male medical doctors.

\section{Acknowledgements}

We thank Dr. Ryoji Yasumizu, Dr. Masashi Shintaku, Dr. Ippei Mori and Dr. Naomi Kitano for their kind suggestion.

\section{References}

1) Takayasu A (1964) Hygienic studies on the air-turbine engine for dental use. Dent Material J 11, 41-70. (in Japanese)

2) Sakuraba Y, Magoshi A, Okada H, Morimoto M, Kidokoro M (1973) Study on cutting dusts generated by dental air-turbine engine. J Dent Health 23, 19-31 (in Japanese).

3) Fukuzawa Y, Nishida M, Morimoto M (1986) A new method employing a laser for observation of dental dust scattering. J Dent Health 36, 215-27 (in Japanese).

4) Brune D, Beltesberkke H, Melsom S (1981) Dust in work room air and dental laboratories. Swed Dent J 5, 247-51.

5) Kidokoro M (1953) The career of dentists. J Jap Dent Assoc 5, 363-74 (in Japanese).

6) Amano I (1956) Hygiene of Denstry. Shikageppo 30, 63-82 (in Japanese).

7) Brune D, Beltesberkke H (1981) Dust in dental laboratories. Part I: Types and levels in specific operation. J Prosthet Dent 43, 687-92.

8) Brune D, Beltesberkke H (1981) Dust in dental laboratories. Part III: Efficiency of ventilation systems and face masks. J Prosthet Dent 44, 211-5.

9) Fukuzawa Y (1987) Study on scattered dust from the polishing of cast framework of denture from the view point of industrial hygiene. J Dent Health 37, 225-43 (in Japanese).

10) Fukuzawa Y, Mochizuki H, Morimoto M (1990) Preliminary report on hard metal dusts in dental polishing work IV. J Dent Health 40, 470-1 (in Japanese).
11) Bargon J, Rust M, Kronenberger H (1990) Stimulation of peripheral lymphocytes with $\mathrm{BeSO} 4$ in dental laboratory technicians with a past history of beryllium exposure. Am Rev Respir Dis 141, A246.

12) Kotlof RM, Richman PS, Greenacre JK, Rossman MD (1993) Chronic beryllium disease in a dental laboratory technician. Am Rev Res Dis 147, 205-7.

13) International Agency for Research on Cancer (IARC) (1990) IARC monographs on the evaluation of carcinogenic risks to humans, Vol.49, IARC, Lyon.

14) IARC (1991) IARC monographs on the evaluation of carcinogenic risks to humans, Vol.52, IARC, Lyon.

15) IARC (1992) IARC monographs on the evaluation of carcinogenic risks to humans, Vol.58, IARC, Lyon.

16) De Vurst P, Vande Weyer R, De Coster A, Marchandise FX, Dumortier P, Ketelbant P, Jedwab J, Yernault JC (1986) Dental technicians pneumoconiosis, a report of two cases. Am Rev Respir Dis 133, 316-20.

17) Loewen GM, Weiner D, Mcmahan J (1988) Pneumoconiosis in an elderly dentist. Chest 93, 1312-3.

18) Barrett TE, Pietra GG, Maycock RL, Possman MD, Minda JM, Johns LW (1989) Acrylic resin pneumoconiosis: report of a case in a dental student. Am Rev Respir Dis 139, 841-3.

19) Choudat D, Triem S, Weill B, Vicrey C, Ameille J, Brochard P, Letourneux M, Rossignol C (1993) Respiratory symptoms, lung function, and pneumoconiosis among self employed dental technicians. Br J Ind Med 50, 443-9.

20) Selden AI (1995) Exposure to cobalt chromium dust and lung disorders. Thorax 50, 769-72.

21) Selden AI, Sahle W, Johansson L, Sorenson S, Persson B (1996) Three cases of dental technicians pneumoconiosis related to cobalt-chromium-molybdnum dust exposure. Chest 109, 837-42.

22) Nishikawa T, Ohmori S, Wato M, Tsutsui J, Nishimura Y, Tanaka A (1993) Deposits of various metallic dusts observed at autopsy in a dental health care worker with lung cancer. Jpn J Oral Biol 35, 251-4 (in Japanese).

23) Liou TC, Chang TT, Young KC, Lin XZ, Lin CY, Wu HL (1992) Detection of HCV RNA in saliva, urine, seminal fluid, and ascites. J Med Virol 37, 197-202.

24) Eijk AA, Niesters HG, Gotz HM, Janssen HL, Schalm SW, Osterhaus AD, Man RA (2004) Paired measurements of quantitative hepatitis B virus DNA in saliva and serum of chronic hepatitis B patients: implications for saliva as infectious agent. J Clin Virol 29, 92-4.

25) IARC (1994) IARC monographs on the evaluation of carcinogenic risks to humans, Vol.59, IARC, Lyon.

26) Anonymous (2001) Preventive measures for $\mathrm{HCV}$ infection, Q \& A, Japan Dental Association, Tokyo (in Japanese).

27) Nishio N, Tanaka H, Tsukuma H, Tokunaga R (2004) Lung cancer risk in male dentists, a retrospective cohort study in Japan. J Occup Health 46, 37-42.

28) Tanaka H, Nishio N, Tokunaga R, Tsukuma H (2004) 
Liver cancer risk in male dentists, a retrospective cohort study in Japan. J Occup Health 46, 398-402.

29) Fujimoto I, Hanai A (1972) Occurrence and medical care of cancer-registration of cancer in Osaka, 16th report. Gan no Rinsho 18, 3-18 (in Japanese).

30) Takiyama W, Moriwaki S, Mandai K, Hara K, Doihara H, Takashima S (1989) The potential esophagus cancer case discovered by autopsy -from 307 autopsy case-. Gan no Rinsho 35, 933-8 (in Japanese).

31) Tomioka T, Yokoyama H, Nozaki S (1988) Examination of the death of a doctor in the dissection case. J Health Welfare Statis 35, 20-6 (in Japanese).

32) Chang N, Kawai S, Kanoh T, Okada R, Kitamura K (1984) A statistical study on the relationship between myocardial infarction and occupations using the annual pathological autopsy cases in Japan, 1980. J Jap Atherosclerosis Soc 12, 1315-20 (in Japanese).

33) Yamamoto M (1993) Relative risk of lung cancer among pneuemoconiosis analyzed from autopsy registration in Japan. JJTOM 41, 729-37 (in Japanese).

34) Minowa M, Aizawa S, Shimizu H, Ohno Y, Nagai M, Yanagawa H (1990) Epidemic characteristics of systemic lupus erythematosus. J Health Welfare Statis 37, 14-8 (in Japanese).

35) Hisaoka $H$ (1996) Trends in mortality from ischemic heart disease, and the relationship between occupation and sudden death in Japan. Juntendo Med J 42, 55-64 (in Japanese).

36) Kawai S, Okada R, Miyauchi K, Suzuki H, Yamaguchi H, Tashiro N (1995) Pathology of sudden cardiac death. JJTOM 43, 493-9 (in Japanese).

37) Tsuda T, Yamamoto E, Babazono A, Mino Y, Ogawa T, Shigemi J, Aoyama H (1994) An epidemiologic research design using the annual of the pathological autopsy cases in Japan. Jpn J Hyg 49, 753-61 (in Japanese).

38) Miettinen O (1976) Estimability and estimation in case-referent studies. Am J Epidemiol 103, 226-35.

39) Wang JD, Wegman DH, Smith TJ (1983) Cancer risks in the optical manufacturing industry. $\mathrm{Br} \mathrm{J}$ Ind Med 40, 177-81.

40) Sitas F, Douglas AJ, Webster EC (1989) Respiratory disease mortality patterns among South African iron moulders. Br J Ind Med 46, 310-5.

41) Chiu YL, Yu TIS (2001) Colorectal cancer among chinese restaurant waiters. Occup Med 51, 343-6.

42) Lee LJH, Chung CW, Y-C Ma YC, G-S Wang GS, Chen PC, Hwang YH, Wang JD (2003) Increased mortality odds ratio of male liver cancer in a community contaminated by chlorinated hydrocarbons in groundwater. Occup Environ Med 60, 364-9.

43) Wacholder S, Silverman DT, McLaughlin JK, Mandel JS (1992) Selection of controls in case-control studies. II; Types of controls. Am J Epidemiol 135, 1029-41.

44) Cochran W (1954) Some methods for strengthening the common $\chi^{2}$ tests. Biometrics 10, 417-51.

45) Takeda K, Kobayashi H (1963) Review of Japanese pathological statistics of lung cancer. Jap J Clin Med 21, 319-24 (in Japanese).

46) Mandai K, Moriwaki S, Yamaguchi K, Saeki T, Yamaguchi M (1994) An analysis of autopsy cases with cancer of unknown primary site. Jpn J Clin Patho 42, 75-82 (in Japanese).

47) Rothman KL (2008) Modern epidemiology third edition, Little Brown and company, Boston.

48) Naoi Y (1979) Composition of occupational prestiege scale. In: Stratums of Japanese Social Structure, Tominaga K (Ed.), 434-72, Tokyo University Press, Tokyo (in Japanese).

49) Coxson APM, Jones CL (1978) The images of occupational prestiege: a study in social cognition. MacMillan Press, London.

50) Ikuta A, Yokoyama E, Simpo H, Nozaki S (1996) Analysis of death among dentists. J Nihon Univ Med Assoc 55, 673-82 (in Japanese).

51) Niwa M, Satoh T, Hoshi A (1999) Research on cause of death of Japanese male dentists. J Health Welfare Statis 46, 32-6 (in Japanese).

52) Pukkala E (1995) Cancer risk by social class and occupation. In: A survey of 10900 cancer cases among Finns of working age, Wahrendorf J (Ed.), 51-7, Karger, Basel.

53) Eklund G, Izikowitz L, Molin C (1990) Malignant tumours in Swedish dental personnel: a comparative study with the total population as well as with some specific occupational groups. Swed Dent J 14, 249-54.

54) Tanaka H, Tsukuma H (1999) Hepatitis C virus. In: Cancer surveys. vol 33. Infection and Human Cancer, Tooze J (Ed.), 213-35, Cold Springer Laboratory Press, NewYork.

55) Aikawa T, Hirayama M, Ishiwatari C (1992) HBV and $\mathrm{HCV}$ infection survey of Japanese health care workers; measurement of HCV-core antibody. J Jpn Med Assoc 107, 679-87 (in Japanese).

56) Shinozaki F, Hayatsu Y, Fukuda T, Suetsugu M, Mizugaki Y (1995) A seroepidemic survey of hepatitis $\mathrm{C}$ virus infection among the dentist in Japan. J Jpn Stomatol Soc 44, 438-41 (in Japanese).

57) Toyoda K, Takata Y, Fujikawa M, Kuroda T, Yao H, Tsuchihashi $\mathrm{T}$ (1996) Needlestick injury among dental personnel. J Kyusyu Dent Assoc 50, 411-4 (in Japanese).

58) Nishio N, Imamura $T$ (2005) Smoking prevalence among dentists in Hyogo, Japan. J Jpn Dent Practice Admin 40, 170-5.

59) Sakurai H, Ohida T (2000) Smoking behavior and attitude to smoking among members of the Japan Medical Association. J Jpn Med Assoc 124, 725-36 (in Japanese).

60) Kaetsu A, Fukushima T, Moriyama M, Shigematsu $T$ (2002) Smoking behavior and related lifestyle variables among physicians in Fukuoka, Japan: a cross sectional study. J Epidemiol 12, 199-207.

61) Kono S, Ikeda M, Tokudome S, Yoshimura T, 
Nishizumi M, Kuratsune M (1985) Alcohol and cancer in male Japanese physicians. J Cancer Res Clin Oncol 109, 82-5.

62) Kishimoto M, Hanioka T, Tanaka M, Shizukuishi S (1997) Lifestyle and health practices of dentists in an alumni association of a dental school in Japan. J Dent Health 47, 240-9 (in Japanese).

63) Takei $T$ (1988) Alcohol drinking and life style of medical students. J Jpn Dent Practice Admin 23, 1-9 (in Japanese).
64) Kobayashi M, Ikeda K, Saitoh S (2000) Incidence of primary cholangiocellular carcinoma of the liver in Japanese patients with hepatitis C virus related cirrhosis. Cancer 88, 2471-7.

65) Yamamoto S, Kubo S, Hai S, Uenishi T, Yamamoto T, Shuto T, Takemura S, Tanaka H, Yamazaki O, Hirohashi K, Tanaka T (2004) Hepatitis C virus infection as a likely etiology of intrahepatic cholangiocarcinoma. Cancer Sci 95, 592-5. 